\title{
FREQUENCY OF SPERMATOPHORE PRODUCTION AND REGENERATION IN THE MALES OF Tityus (Atreus) magnimanus POCOCK, 1897 (Scorpiones, Buthidae)
}

\section{Ross LK (1)}

(1) Member of the American Arachnological Society, American Entomological Society and International Society of Arachnology.

ABSTRACT: The frequency of spermatophore production and the amount of time between matings for laboratory-reared males of Tityus (Atreus) magnimanus to regenerate spermatophores were examined. Males attain sexual maturity at the fifth or sixth instar (after a period of 137 to 155 days) and can produce initial spermatophores shortly after maturation. After mating, males can regenerate spermatophores within a single 24-hour period and remate. The present contribution represents the first report on an aspect of reproductive biology in this species and is part of a continuing study of the life history and post-embryonic development of Tityus (Atreus) magnimanus.

KEY WORDS: scorpions, Buthidae, Tityus (Atreus) magnimanus, courtship, mating, spermatophores, sperm transfer.

CONFLICTS OF INTEREST: There is no conflict.

\section{CORRESPONDENCE TO:}

LUCIAN K. ROSS, 6303 Tarnow, Detroit, Michigan 48210-1558, USA. Phone: +1 313 285-9336. Email: lucian.ross@yahoo.com. 
Ross LK. Frequency of spermatophore production and regeneration in the males of Tityus (Atreus) magnimanus Pocock, 1897 (Scorpiones, Buthidae). J Venom Anim Toxins incl Trop Dis. 2009;15(1):158

\section{INTRODUCTION}

Courtship and mating among scorpions involves a complex series of ritualized acts leading up to sperm transfer to females via an external stationary spermatophore (14). Courtship and mating behaviors in scorpions have been described in thirty species and typically involve the male initiating courtship by grasping female chelae within his own and leading her in a series of coordinated movements until a suitable surface is located, upon which the spermatophore will be deposited $(3,4)$. Once a suitable surface is selected, the male lowers his body and the hemispermatophores slide out of the paired paraxial organs, move into the genital atrium where the two hemispermatophores are joined, forming the completed spermatophore, and the pedicel is attached to the surface chosen by the male.

The spermatophores of male scorpions are divided into two basic types: flagelliform and lamelliform (5). The family Buthidae C. L. Koch, 1837 is characterized by flagelliform spermatophores while other scorpion families, on which such data is available, possess lamelliform spermatophores (5). Flagelliform spermatophores consist of three basic parts: the pedicel that attaches to the surface selected by the male (the first part of the spermatophore to be extruded); the rod-like trunk that contains the sperm vesicle and the sperm duct opening; and the flagellum which represents the free, distal end of the spermatophore, and in some species can stretch to forty times its length (6).

Males of most, if not all, scorpion species are capable of mating more than once (3). Based on a substantial number of published reports (7-12), there exists considerable evidence that recently mated males can produce new spermatophores and remate in a very short period of time. In one published account, a single male Tityus (Tityus) bahiensis (Perty, 1834) mated 11 times in 102 days, with six days being the minimum reported time between successive matings (8). The present contribution provides the first reported data on the number of molts up to maturity and frequency of spermatophore production in the medically significant scorpion species Tityus (Atreus) magnimanus Pocock, 1897 (Buthidae).

During laboratory observations of courtship and mating sequences in the buthid scorpion Tityus (Atreus) magnimanus, the frequency of spermatophore production between successive matings were recorded as part of a continuing series of life history studies of this species. Tityus (Atreus) magnimanus is a medium size (60 to 
$70 \mathrm{~mm}$ ), reddish to reddish-brown scorpion species endemic to tropical altitudinal forest in Falcón and Lara states, north-central Venezuela.

Males of Tityus (Atreus) magnimanus were mature at the fifth or sixth instar (in 130 to 152 days) and females at the sixth instar (after a period of 172 to 190 days) (Ross, personal observation). Attaining sexual maturity at different instars is a common life history strategy among buthid scorpions (13). Francke and Sissom (14) reported the number of developmental instars in 32 scorpion species, with $47 \%(n=15)$ maturing at multiple instars within the same sex. Polymorphic maturation has been previously reported to occur in several members of the genus Tityus C. L. Koch, 1836 (3).

For this study, ten unrelated adult males of known age were randomly selected. Of the ten males, eight matured at the fifth instar, after 130 to 147 days, and two at the sixth instar, after 148 and 152 days. After their maturing molts, males were provided a 72-hour recuperative period. Beginning on the fourth day after maturing molts, males were randomly paired with laboratory reared females $(n=30)$ of known age on successive days in order to determine the number of days required for males to produce their initial spermatophores. As soon as mating occurred and a spermatophore was deposited and sperm transfer completed, participants were separated from each other and the males returned to individual containers and the date of each spermatophore deposition was recorded for each animal. Mature males of fifth $(n=1)$ and sixth instars $(n=1)$ were able to produce initial spermatophores six days after their maturing molts. The remaining males of fifth $(n=7)$ and sixth instars $(n=1)$ produced initial spermatophores seven days after their maturing molts (Table 1). 
Ross LK. Frequency of spermatophore production and regeneration in the males of Tityus (Atreus) magnimanus Pocock, 1897 (Scorpiones, Buthidae). J Venom Anim Toxins incl Trop Dis. 2009;15(1):160

Table 1. Spermatophore production and regeneration time in ten males of Tityus (Atreus) magnimanus

\begin{tabular}{|c|c|c|c|c|c|}
\hline $\begin{array}{l}\text { Specimen } \\
\text { ID }\end{array}$ & $\begin{array}{l}\text { Maturing } \\
\text { molt } \delta^{\gamma}\end{array}$ & $\begin{array}{l}\text { Maturing } \\
\text { instar }{ }^{\lambda}\end{array}$ & $\begin{array}{l}\text { Initial } \\
\text { mating }\end{array}$ & $2^{\text {nd }}$ mating & $3^{\text {rd }}$ mating \\
\hline $\operatorname{Tm}{ }^{\lambda} \mathrm{G} 1-01$ & 18/II/2008 & 5 & $24 / I / / 2008$ & 26/II/2008 & $28 / 11 / 2008$ \\
\hline $\operatorname{Tm} \widehat{A} \mathrm{G} 1-02$ & $20 / I I / 2008$ & 5 & 26/II/2008 & 28/II/2008 & $01 / I I I / 2008$ \\
\hline $\operatorname{Tm} \widehat{G} 1-03$ & 02/III/2008 & 5 & 08/III/2008 & 10/III/2008 & $12 / I I I / 2008$ \\
\hline $\operatorname{Tm}{ }^{\lambda} \mathrm{G} 1-04$ & 05/III/2008 & 5 & 11/III/2008 & 13/III/2008 & 15/III/2008 \\
\hline $\operatorname{Tm} \widehat{A} \mathrm{G} 1-05$ & 05/III/2008 & 5 & 12/III/2008 & 14/III/2008 & 16/III/2008 \\
\hline $\operatorname{Tm} \widehat{A} \mathrm{G} 1-06$ & 10/III/2008 & 5 & 16/III/2008 & 18/III/2008 & $20 / I I I / 2008$ \\
\hline $\operatorname{Tm}{ }^{\lambda} \mathrm{G} 1-07$ & 16/III/2008 & 5 & $22 / I I I / 2008$ & $24 / I I I / 2008$ & $26 / I I I / 2008$ \\
\hline $\operatorname{Tm} \widehat{A} \mathrm{G} 1-08$ & 22/III/2008 & 5 & 28/III/2008 & 01/IV/2008 & 03/IV/2008 \\
\hline $\operatorname{Tm} \widehat{A} \mathrm{G} 1-09$ & 28/III/2008 & 6 & 05/IV/2008 & 07/IV/2008 & 09/IV/2008 \\
\hline $\mathrm{Tm}^{\wedge} \mathrm{G} 1-10$ & 01/IV/2008 & 6 & $07 / \mathrm{IV} / 2008$ & 09/IV/2008 & 11/IV/2008 \\
\hline
\end{tabular}

Subsequent to each initial mating, males were provided a 24-hour recuperative period before being introduced into mating arenas containing previously unmated females on successive days. If mating did not occur within two hours, males were removed and returned to their respective enclosures. Each of the ten males was allowed to mate with three different previously unmated females of known age in order to assess the frequency of spermatophore regeneration. During successive mating trials, males $(n=10)$ were capable of producing new spermatophores within 24-hours and successfully remating in a very short period of time, with the period between spermatophore regeneration for each male limited to 24 hours.

The time for spermatophore regeneration in Tityus (Atreus) magnimanus is the shortest one registered for males of any scorpion species. Additional studies are 
Ross LK. Frequency of spermatophore production and regeneration in the males of Tityus (Atreus) magnimanus Pocock, 1897 (Scorpiones, Buthidae). J Venom Anim Toxins incl Trop Dis. 2009;15(1):161

being conducted to assess the potential costs of rapid spermatophore regeneration and high rates of mating and their effects on longevity in males of this species.

\section{ACKNOWLEDGEMENTS}

Special thanks are extended to Jan Ove Rein (Norwegian Institute of Science and Technology, Trondheim, Norway) for his helpful comments and suggestions on a previous version of this study and to three anonymous reviewers for their comments and suggestions on the final version of this manuscript. Additional thanks are extended to Professor Wilson R. Lourenço (Muséum National d'Histoire Naturelle, Paris, France) for sharing his extensive knowledge of the genus Tityus with the author.

\section{REFERENCES}

1. Alexander AJ. Courtship and mating in the buthid scorpions. Proc Zool Soc London. 1959;133:145-69.

2. Lourenço WR. Reproduction in scorpions, with special reference to parthenogenesis. In: Toft S, Scharff N, editors. European Arachnology 2000. Proceedings of the $19^{\text {th }}$ European Colloquium of Arachnology; 2000 July 17-22 july 2000. Åarhus, Denmark: Åarhus University Press; 2002. p. 71-85.

3. Polis GA, Sissom WD. Life history. In: Polis GA, (editor). The Biology of scorpions. Stanford: Stanford University Press; 1990. p. 161-223.

4. Tallarovic SK, Melville JM, Brownell PH. Courtship and mating in the giant desert hairy scorpion, Hadrurus arizonensis (Scorpionida, luridae). J Insect Behav. 2000;13(6):827-38.

5. Francke OF. Spermatophores of some North American scorpions (Arachnida, Scorpiones). J Arachnol. 1979;7:19-32.

6. Bücherl W. Escorpiões e escorpionismo no Brasil. V. Observações sobre o aparelho reprodutor masculino e o acasalamento de Tityus trivittatus e Tityus bahiensis. Mem Inst Butantan. 1956;27:121-55.

7. Koch LE. The taxonomy, geographic distribution and evolutionary radiation of Australo-Papuan scorpions. Rec West Aust Mus. 1977;5(2):83-367. 
8. Matthiesen FA. On the male reproductive organs in some Brazilian scorpions. Rev Brasil Pesq Med Biol. 1968;1(5-6):273-4.

9. Matthiesen FA. Sôbre o acasalamento de Tityus bahiensis (Perty, 1834). Rev Agric. 1960;35(4):341-6.

10. Maury EA. Observaciones sobre el ciclo reproductivo de Urophonius brachycentrus (Thorell, 1877) (Scorpiones, Bothriuridae). Physis. 1969;29(78):131-9. 11. Probst $P$. Zur fortpflanzungsbiologie und zur entwicklung der giftdrüsen beim skorpion Isometrus maculatus (DeGeer, 1778) (Scorpiones: Buthidae). Acta Trop. 1972;29:1-87.

12. Shulov A, Amitai P. On mating habits of three scorpions: Leiurus quinquestriatus H. et F., Buthotus judaicus E. Sim. and Nebo hierichonticus E. Sim. Arch Inst Pasteur Alger. 1958;36(3):351-69.

13. Francke OF, Jones SK. The life history of Centruroides gracilis (Scorpiones, Buthidae). J Arachnol. 1982;10:223-39.

14. Francke OF, Sissom WD. Comparative review of the methods used to determine the number of molts to maturity in scorpions (Arachnida), with an analysis of the postbirth development of Vaejovis coahuilae Williams (Vaejovidae). J Arachnol. 1984;12:1-20. 